\title{
Synthesis and characterization of phosphorus doped hydrogenated silicon films by filtered cathodic vacuum arc technique
}

\author{
Ajay Kesarwani, O. S. Panwar, R. K. Tripathi and Sreekumar Chockalingam \\ Polymorphic Carbon Thin Films Group, Physics of Energy Harvesting Division, \\ CSIR-National Physical Laboratory, Dr. K. S. Krishnan Marg, New Delhi-110012, India. \\ E-mail: ospanwar@mail.nplindia.ernet.in
}

\begin{abstract}
Phosphorous doped hydrogenated silicon thin film has been deposited by filtered cathodic vacuum arc technique at different substrate temperatures at a fixed hydrogen gas pressure. X-ray diffraction, electrical conductivity and optical band gap and scanning electron microscopy have been used to characterize the properties of films.
\end{abstract}

Index Terms- Filtered cathodic vacuum arc, X-ray diffraction, Conductivity, Activation energy, Optical band gap, $P$ doped hydrogenated silicon film.

\section{INTRODUCTION}

Silicon, the second most abundant element on earth has been receiving great attention for last few decades because of their many potential applications in various functional devices. Single crystal silicon is effectively applied in the development of photovoltaic materials, single electrical transistors, micro-electromechanical systems, resonanttunneling diodes, super lattice devices etc. Microcrystalline silicon $(\mu \mathrm{c}-\mathrm{Si})$, also called nanocrystalline silicon (nc-Si) on the basis of crystal size in many cases is considered as one of the most promising thin-film material. It exhibits unique physical, electronic and optical properties and has varieties of promising technological applications in thin film photovoltaic devices, thin film transistors and image sensors [1-4] etc. nc$\mathrm{Si}$ thin film has a two-phase structure consisting of nc-Si embedded in a matrix of amorphous silicon. Their promise lie in the hope of achieving a better quality material at relatively low manufacturing costs mostly because of the low temperature at which nc-Si is grown. In thin film solar cells, due to higher mobility, reduced light induced degradation [5] and enhanced absorption in the near infrared wavelength range, nc- Si significantly exhibits higher energy conversion efficiencies than amorphous silicon. So far, the production of nc-Si thin films have been focused on some deposition techniques such as plasma enhanced chemical vapor deposition (PECVD), hot wire chemical vapor deposition (HWCVD), inductively coupled plasma enhanced chemical vapor deposition (IC-PECVD) [6-10] etc. by decomposing monosilane or disilane gas. The silane gas employed in the growth of film is flammable and the doping gases like diborane and phosphine are highly toxic in nature. Thus, a proper solution to this problem is to grow these thin films from solid silicon target without introducing any toxic gases in the deposition chamber.

We report a new and simple filtered cathodic vacuum arc
(FCVA) technique for the synthesis of phosphorous doped hydrogenated silicon $(\mathrm{Si}: \mathrm{H})$ film. The cathodic vacuum arc is generally produced from cold cathodes whose material has to be deposited. The material flux emitted by explosion or by evaporation is composed of ions, neutral atoms, electrons and micro droplets of the material to be deposited. Ionized vapor of the material created in cathodic arc enhances the ability to independently control ion flux and ion energy at the substrate. It also allows better control of ion bombardment of the growing film and better thickness homogeneity by applying external bias and temperature. The energy of ionized particle is between 10 and $60 \mathrm{eV}$ depending upon the depositing material which can be enhanced by applying negative bias to the substrate. One of the main advantages of FCVA process is a high growth rate process where no hazardous gases like $\mathrm{SiH}_{4}, \mathrm{~B}_{2} \mathrm{H}_{6}$ and $\mathrm{PH}_{3}$ are used to deposit doped silicon films. FCVA is plasma based popular industrial technology for the deposition of variety of films like metals, ceramics, diamondlike carbon and tetrahedral amorphous carbon films [11-17]. It is a low voltage and high current process that takes place between two electrodes. FCVA method has been used earlier to deposit amorphous silicon thin films [18, 19]. This technique has also been used to deposit boron doped tetrahedral amorphous carbon film as a window layer in the inline production of large area amorphous silicon solar cell for improving the efficiency [20]. Phosphorous doped Si: H thin films have been deposited by FCVA technique at different substrate temperatures with hydrogen gas dilution. In this work, we studied the structural, optical and electrical properties of the $\mathrm{P}$ doped hydrogenated Si thin films.

\section{EXPERIMENTAL DETAILS}

$\mathrm{P}$ doped $\mathrm{Si}$ : $\mathrm{H}$ thin films have been prepared by FCVA technique. A detailed description of the system has been described elsewhere [17]. The FCVA process works on the principle of striking the arc (arc voltage of 35-40 V with an arc current of $100 \mathrm{~A})$ between two electrodes. Here, one electrode is phosphorus doped $(0.55 \Omega \mathrm{cm})$ silicon cathode of $50 \mathrm{~mm}$ diameter and $5 \mathrm{~mm}$ thick of purity $99.999 \%$ that works as silicon source in order to deposit P doped thin film. Second electrode is a retractable high purity tungsten wire as an anode. The magnetic filter is energized using direct current (D.C.) power supply and a magnetic field of $\sim 350 \mathrm{G}$ is achieved inside the duct to remove the macro particles generated from the plasma. Prior to the deposition, the chamber was evacuated to a base pressure of around $\sim 10^{-6}$ mbar. The $\mathrm{P}$ doped Si: $\mathrm{H}$ films were grown at different 
substrate temperature of room temperature $\left(27{ }^{\circ} \mathrm{C}\right)$ and $225{ }^{\circ} \mathrm{C}$ with hydrogen gas dilution at a pressure of $2.5 \times 10^{-3} \mathrm{mbar}$.

The substrate used for the deposition of P doped Si: $\mathrm{H}$ thin films were 7059 corning glass for optical, electrical and x-ray diffraction studies and crystalline silicon wafer for scanning electron microscopy studies. The films are deposited sequentially for $10 \mathrm{sec}$ and then cooled down for $50 \mathrm{sec}$. All the samples were $\sim 100 \mathrm{~nm}$ thick as measured by Talystep (Rank Taylor and Hobson) thickness profiler. The deposition rate of $\mathrm{P}$ doped silicon films was calculated to be $\sim 1.0-1.5$ $\mathrm{nm} / \mathrm{sec}$. Crystallographic structure of the P doped $\mathrm{Si}$ : $\mathrm{H}$ thin films were examined using an X-ray diffractometer (Philips X'Pert PRO PAN analytical) equipped with $\mathrm{CuK}_{\alpha}(1.54 \AA ̊)$ radiation. The dark conductivity $\left(\sigma_{\mathrm{D}}\right)$ has been measured in a gap cell geometry under vacuum $\left(10^{-6} \mathrm{mbar}\right)$. The activation energies $(\Delta \mathrm{E})$ of the deposited films were determined from the slope of the variation of conductivity with inverse of temperature plot. Optical transmittance measurements were performed in the $250-1000 \mathrm{~nm}$ spectral range with a Perkin Elmer spectrophotometer (Lambda 950). The surface morphology of the films was observed using a scanning electron microscope (model JEOL, JSM-35 instrument).

\section{RESULTS \& DISCUSSIONS}

The X-ray diffraction patterns of $\mathrm{P}$ doped $\mathrm{Si}$ : $\mathrm{H}$ films deposited at different substrate temperature with constant hydrogen gas pressure of $2.5 \times 10^{-3}$ mbar are shown in Fig. 1 . The P doped Si: $\mathrm{H}$ film grown at room temperature shows only a broad pattern at around $26^{0}$ which indicates that the room temperature grown film is amorphous in nature. The only features observed for the film grown at $225^{\circ} \mathrm{C}$ are the strong peak occurring at $28^{\circ}$ and less intense peak occurs at $46.96^{\circ}$ which correspond to (111) and (220) crystal orientations, respectively [21-23]. This indicates that the $\mathrm{P}$ doped $\mathrm{Si}: \mathrm{H}$ thin film deposited at substrate temperature of $225^{\circ} \mathrm{C}$ is nanocrystalline in nature. The peak (111) is dominant with respect to the (220) peak. This result indicates that the crystallites in the $\mathrm{P}$ doped $\mathrm{Si}$ : $\mathrm{H}$ film has preferential orientation in the (111) direction. The other noticeable change observed in the diffraction pattern are the broadening and enhancement of intensity of (111) diffraction peak as compared to (220) plane. The size of Si nanocrystals in the film is calculated from the Scherrer formula. The crystallite size calculated from the Scherrer formula is found to be $\sim 63$ $\mathrm{nm}$ and $\sim 75 \mathrm{~nm}$ corresponding to (111) and (220) crystal planes. The enhancement of intensity in XRD patterns is related to the increase in the crystallite fraction. The hydrogen gas dilution plays an important role in the preparation of nanocrystalline silicon (nc-Si) films. The atomic hydrogen etches out the random network or low energy bonded silicon atom at high temperature and favors the nucleation and ordered microcrystal growth. This result may be correlated with the electrical properties of $n$ type nc-Si: $\mathrm{H}$ thin films grown at $225{ }^{\circ} \mathrm{C}$.

Fig. 2 shows the variation of dark conductivity $\left(\sigma_{D}\right)$ of $P$ doped Si: $\mathrm{H}$ films deposited at different substrate temperatures versus inverse of temperature. It is evident from the figure that variation of $\sigma_{\mathrm{D}}$ is a thermally activated process which follows a relation of the form: $\sigma_{\mathrm{D}}=\sigma_{0} \exp (-\Delta \mathrm{E} / \mathrm{kT})$ where $\sigma_{0}$ is the pre exponential factor, $\mathrm{k}$ is the Boltzmann's constant, $\mathrm{T}$ is temperature in Kelvin and $\Delta \mathrm{E}$ is the activation

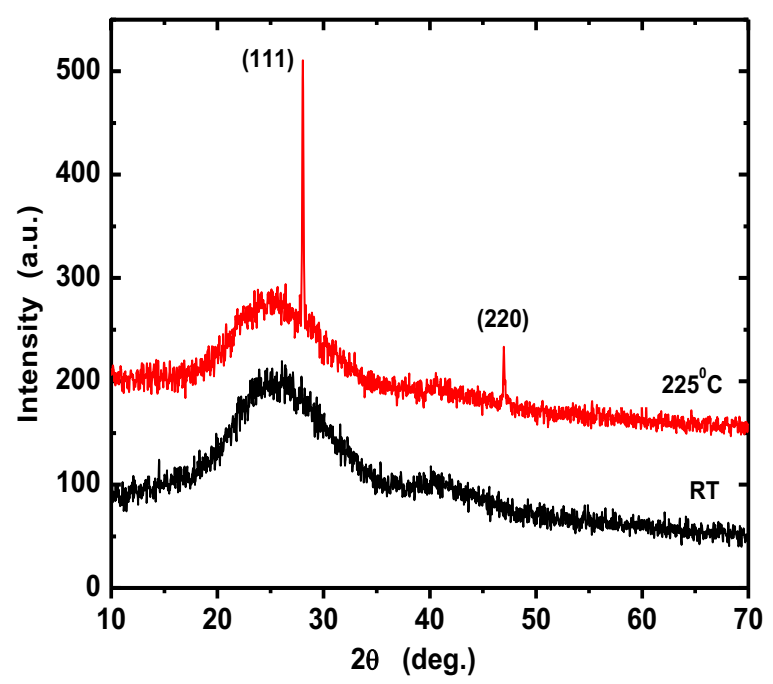

FIG. 1 X-ray patterns of P doped Si: H films deposited at different substrate temperatures.

energy. The variations of dark conductivity $\left(\sigma_{\mathrm{D}}\right)$ and activation energy $(\Delta \mathrm{E})$ of $\mathrm{P}$ doped $\mathrm{Si}: \mathrm{H}$ films grown versus the deposition temperature have been shown in Fig. 3. It may be seen from Fig. 3 that for a hydrogen gas pressure of $2.5 \times 10^{-3}$ mbar, $\sigma_{\mathrm{D}}$ increases from $5.87 \times 10^{-4} \mathrm{ohm}^{-1} \mathrm{~cm}^{-1}$ to $0.019 \mathrm{ohm}^{-1} \mathrm{~cm}^{-1}$ as substrate temperature increases from room temperature (RT) to $225{ }^{\circ} \mathrm{C}$ indicating a transition from the amorphous to the nanocrystalline phase. At high substrate temperature, longer diffusion length of the precursors helps in the nucleation and growth of the ordered nanocrystalline phase. The gas dilution is expected to increase the concentration of atomic hydrogen in the plasma which reacts with the weakly bonded radicals on the growing surface and finally etches them out. This etching action is more prominent in the amorphous region compared to that in the strongly bonded crystalline region in this amorphous-nanocrystalline mixed phase material which helps in the formation of

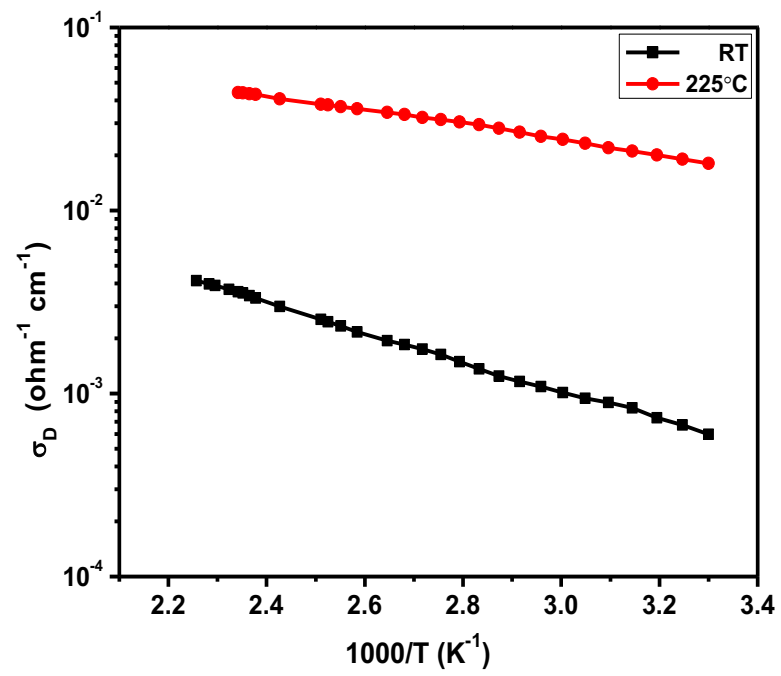

FIG. 2 Variation temperature dependence of dark conductivity of $\mathrm{P}$ doped Si: $\mathrm{H}$ thin films versus inverse of temperatures. 
nanocrystallinity in the Si: $\mathrm{H}$ film. The higher values of $\sigma_{\mathrm{D}}$ of doped nc-Si: $\mathrm{H}$ films compared to those for doped a-Si: $\mathrm{H}$ films arise from the higher mobility of the charge carriers and higher doping efficiency. Although the incorporation of phosphorus in the material may increase with the increase of temperature, a significant amount of dopants is expected to be incorporated in the films in the ionized states, which will increase carrier concentration and thus the conductivity of the film. Moreover, the partial ordering in the network that occurs in $\mathrm{nc}-\mathrm{Si}: \mathrm{H}$ compared to that in a-Si: $\mathrm{H}$ is sufficient to reduce the tail states significantly and move the Fermi level close to the conduction band. This is corroborated by the reduction of the activation energy $(\Delta \mathrm{E})$ from 0.32 to $0.16 \mathrm{eV}$ as shown in Fig. 3. The electrical conductivity and activation energy evaluated of FCVA deposited P doped Si: H films are comparable to those of PECVD [24, 25] deposited films.

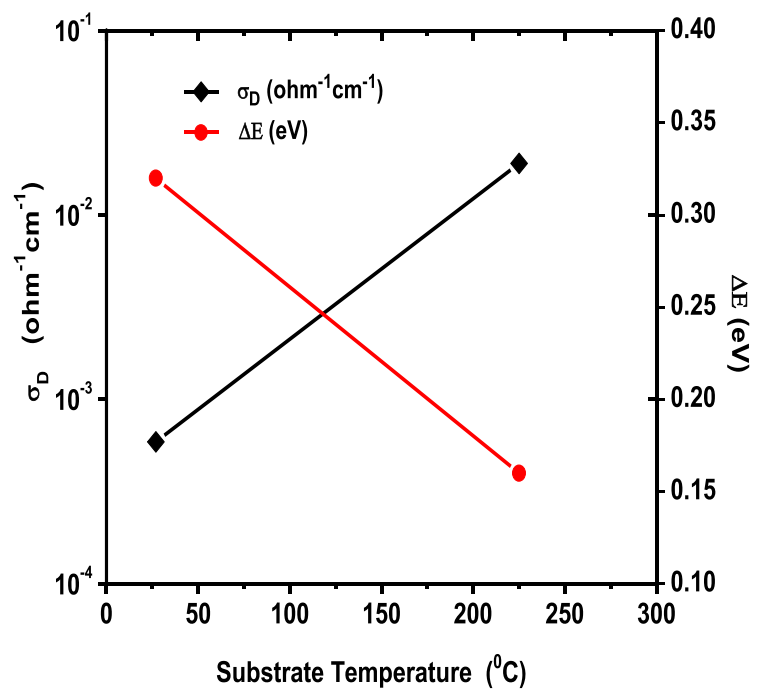

FIG. 3 Variation of dark conductivity $\left(\sigma_{\mathrm{D}}\right)$ and activation energy $(\Delta \mathrm{E})$ of $\mathrm{P}$ doped $\mathrm{Si}: \mathrm{H}$ films grown versus deposition temperature.

The change in the film structure has an important influence on the optical absorption of the film. The optical band gap $\left(E_{g}\right)$ for all the samples is determined from the Tauc equation $\left[(\alpha h v)^{1 / 2}=A\left(h v-E_{g}\right)\right]$ in the fundamental absorption region using the transmittance spectra. Fig. 4 shows the variation of $(\alpha h v)^{1 / 2}$ vs hv of $\mathrm{P}$ doped $\mathrm{Si}: \mathrm{H}$ films grown at different substrate temperature. It may be noted from Fig. 4 that the film deposited at higher value of substrate temperature has less value $(1.6 \mathrm{eV})$ of optical band gap. The corresponding films are n-type nc-Si: $\mathrm{H}$ which has been corroborated by the high dark conductivities of the films deposited at high substrate temperature of $225{ }^{0} \mathrm{C}$ (Fig. 2). But the film deposited at room temperature has high optical band gap of $\sim 1.9 \mathrm{eV}$ which shows the amorphous nature of film. Moreover, microcrystallinity in n-type Si: $\mathrm{H}$ films can also be achieved by increasing the hydrogen dilution at substrate temperature of more than $300^{\circ} \mathrm{C}$. The energy bands and the band gap of $\mu \mathrm{c}-\mathrm{Si}: \mathrm{H}$ is still poorly understood. The optical band gap of $\mu \mathrm{c}-\mathrm{Si}$ : $\mathrm{H}$ is found between the band gap of a-Si: $\mathrm{H}$ and $\mathrm{c}-\mathrm{Si}$. This can be attributed to the nondirect transitions occurring in the disordered tissue forming the grain

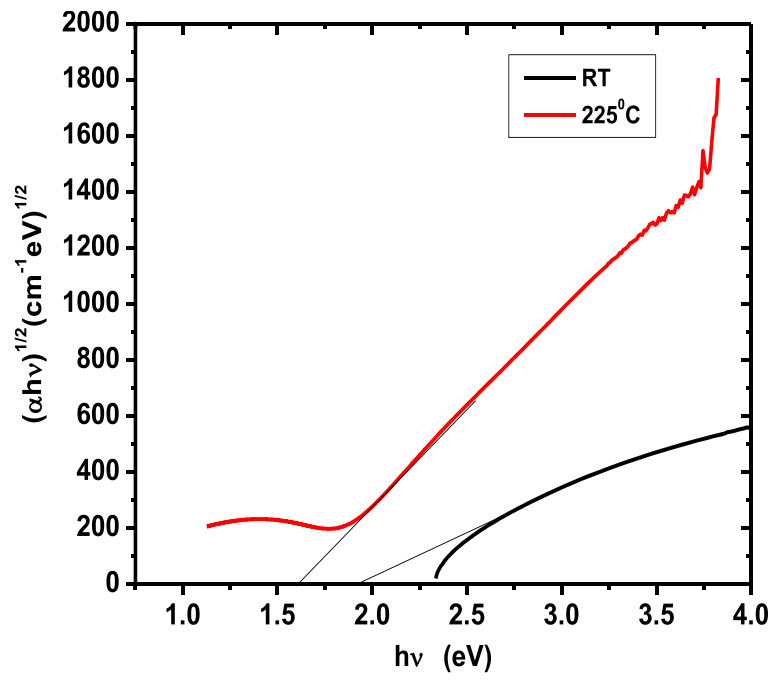

FIG. 4 Variation of $(\alpha h v)^{1 / 2}$ vs hv of P doped Si: H films grown at different substrate temperature.

boundaries. The structure of $\mu \mathrm{c}-\mathrm{Si}$ : $\mathrm{H}$ materials include nanometer-sized crystallites, grain boundaries and amorphous tissues. The disordered bonds are formed between the silicon and hydrogen at the grain boundary region and in the
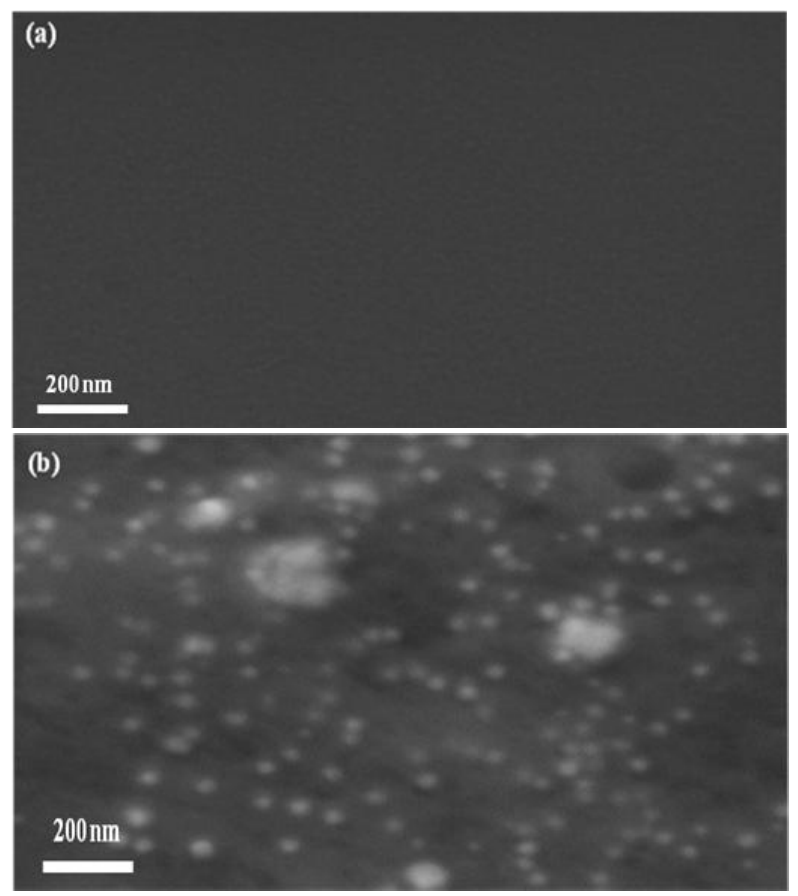

FIG. 5. SEM images of $P$ doped Si: $H$ thin films deposited at (a) RT (b) $225^{\circ} \mathrm{C}$.

amorphous tissues which are main sources of absorption of optical radiation in the $\mu \mathrm{c}-\mathrm{Si}: \mathrm{H}$ films. Thus, the absorption is lower than that for a-Si: $\mathrm{H}$ due to the smaller volume fraction of amorphous tissue in the $\mu \mathrm{c}-\mathrm{Si}$ : $\mathrm{H}$ but the optical absorption in the high energy region is different in the material. The high optical band gap of a-Si: $\mathrm{H}$ films can be correlated with the 
low dark conductivity and large activation energy of material as shown in Fig. 3.

Fig. 5 shows the SEM micrographs of the P doped $\mathrm{Si}: \mathrm{H}$ films deposited at different temperatures of (a) RT and (b) $225{ }^{\circ} \mathrm{C}$, respectively. It is evident from the micrographs that the films deposited at RT have smooth surface and do not demonstrate any type of nanostructure whereas grains start appearing when the temperature of deposition was increased from RT to $225{ }^{\circ} \mathrm{C}$. It is seen in Fig. 5(a) that there is no appearance of crystal growth in the film but the shape and size of nanocrystals visible in the films are affected by the increase of temperature as shown in Fig. 5(b).

\section{CONCLUSIONS}

Phosphorus doped Si: $\mathrm{H}$ thin films have been deposited at different substrate temperatures of room temperature (RT) and $225{ }^{\circ} \mathrm{C}$. The XRD patterns show that RT grown film is amorphous in nature but high temperature deposited film is crystalline in nature with (111) and (220) crystal orientation. The dark conductivity of silicon film deposited with hydrogen gas was found to vary from $5.87 \times 10^{-4} \mathrm{ohm}^{-1} \mathrm{~cm}^{-1}$ to 0.019 $\mathrm{ohm}^{-1} \mathrm{~cm}^{-1}$ and activation energy varies from $0.32 \mathrm{eV}$ to 0.16 $\mathrm{eV}$ on increasing the substrate temperature from $\mathrm{RT}$ to $225^{\circ} \mathrm{C}$. The growth mechanism of film was discussed. The properties of FCVA deposited phosphorus doped hydrogenated nc-Si films were found to be comparable to the P doped nc- Si films prepared by different chemical vapor deposition techniques such as HWCVD, ICP-CVD and PECVD.

\section{ACKNOWLEDGEMENT}

The authors are grateful to Prof. R. C. Budhani, Director, CSIR-National Physical Laboratory, New Delhi (India) for his kind permission to publish this paper. They wish to thank to Dr. Sushil Kumar, Mr. C. M. S. Rauthan and Mr. Atul Bisht for useful discussion. Mr. Ajay Kumar Kesarwani is grateful to the Council of Scientific and Industrial Research (CSIR), Government of India and Mr. R. K. Tripathi is grateful to the Ministry of New and Renewable Energy (MNRE), Government of India for providing financial assistant during the course of this work.

\section{REFERENCES}

[1] S. Sriraman, S. Agrawal, E. S. Aydil, D. Maroudas, Nature 418 (2002) 62.

[2] Biaggi-Labiosa, F. Sol'a, O. Resto, L. F. Fonseca, A. Gonz'alez-Berr'1os, J. De Jes'us J De, G. Morell, Nanotechnol. 19 ( 2008) 225202.

[3] D. Y. Song, D. Inns, A. Straub, M. L. Terry, P. Campbell, A. G. Aberle, Thin Solid Films 513 (2006) 356.

[4] A. V. Shah, J. Meier, E. V. Sauvain, N. Wyrsch, U. Kroll, C. Droz, U. Graf, Solar Energy Mater. Sol. Cells 78 (2003) 469.

[5] S. Paul, Solar Energy Mater. Sol. Cells 78 (2003) 349

[6] H. D. Yang, C. Y. Wu, J. K. Huang, R. Q. Ding, Y. Zhao, X. H. Geng, S. Z. Xiong, Thin Solid Films 472 (2005) 125.

[7] D. Y. Song, E.C. Cho, G. Conibeer, C. Flynn, Y.D. Huang, M.A. Green, Solar Energy Mater. Sol. Cells 92 (2008) 474.

[8] B.Yan, C. S. Jiang, C. W. Teplin, H. R. Moutinho, M. M. Al-Jassim, J. Yang, S. Guha, J. Appl. Phys. 101 (2007) 033712.

[9] V. S. Waman, M. M. Kamble, S. S. Ghosh, A. Mayabadi, V. G. Sathe, D. P. Amalnekar, H. M. Pathan, S. R. Jadkar, J. Nanosci. Nanotechnol. 12 (2012) 8459.

[10] W. C. Choi, C. K. Kim, E. K. Kim, C. M. Shim, D. Jung, C. Y. Park, J. Korean Physical Soc. 36 (2000) 23.

[11] J. Robertson, Mater. Sci. Eng. R, 37 (2002) 129.

[12] P. J. Fallon, V. S. Veerasamy, C. A. Davis. J. Robertson, G. A. J. Amaratunga, W. I. Milne, J. Koskinen, Phys. Rev. B 48 (1993) 4777.

[13] P. J. Martin, A1.4 Cathodic Arc Deposition, Handbook of Thin Film Process Technology, IOP Publishing Ltd., 1995.

[14] O. S. Panwar, Y. Aparna, S. M. Shivaprasad, M. A. Khan, B. S. Satyanarayana, R. Bhattacharyya, Appl. Surf. Sci. 221 (2004) 392.

[15] O. S. Panwar, B. Deb, B. S. Satyanarayana, M. A. Khan, R. Bhattacharyya, A. K. Pal, Thin Solid Film 472 (2005) 180.

[16] O. S. Panwar, M. A. Khan, G. Bhagavanarayana, P. N. Dixit, Sushil Kumar, C. M. S. Rauthan, Indian J. Pure and Appl. Phys. 46 (2008) 797.

[17] O. S. Panwar, M. A. Khan, B. Bhattacharjee, A. K. Pal, B. S. Satyanarayana, P. N. Dixit, R. Bhattacharyya, M. Y. Khan, Thin Solid Films 515 (2006) 1597.

[18] R. L. Boxman, S. Goldsmith, A. B. Shalom, L. Kaplan, D. Arbilly, E. Gidalevich, V. Zhitomirsky, A. Ishaya, M. Keidar, I. I. Beilis, IEEE Transactions on plasma science 23 (1995) 939.

[19] M. M. M. Bilek, W.I. Milne, Thin Solid Films 290-291(1996) 299.

[20] J. Han, M. Tan, J. Zhu, S. Meng, B. Wang, S. Mu, D. Cao, Appl. Phys. Lett. 90 (2007) 083508.

[21] Y. Sakuma, H. Liu, H. Shirai, Y. Moriya, H. Ueyama, Thin Solid Films $386(2001) 256$

[22] V. L. Dalal, J. Graves, J. Leib, Appl. Phys. Lett. 85 (2004) 1413.

[23] K. Bruhne, M. B. Schuberk, C. Kohler, J. H. Werner, Thin Solid Films, $396(2001) 163$.

[24] M. F. Baroughi, S. Sivoththaman, Semicond. Sci. Technol. 21 (2006) 979.

[25] O. S. Panwar, C. Mukherjee, R. Bhattacharya, Solar Energy Mater. Sol. Cells 57 (1999) 373. 